\title{
A Gestão Pública de Tupã/SP para o enfrentamento da pandemia do Covid-19
}

The Public Management of Tupã / SP to face the Covid-19 pandemic

La Gestión Pública de Tupã / SP para afrontar la pandemia Covid-19

Sandra Medina Benini

Pós-Doutorado em Arquitetura e Urbanismo pela FAAC/UNESP, Brasil. Docente da FAIP e Diretora do Departamento de Estudo e Pesquisa Científica da ANAP arquiteta.benini@gmail.com

Elisângela Medina Benini

Advogada e Pesquisadora da ANAP elisangela@jmoreira.net 


\section{Revista Científica ANAP Brasil}

ISSN 1984-3240 - Volume 14, número 32, 2021

\section{RESUMO}

Este artigo teve como objetivo realizar uma análise da pandemia do Covid-19 no município de Tupã, considerando as medidas jurídicas adotadas pela prefeitura em manter as atividades não essenciais abertas, contrariando as recomendações do Governo do Estado de São Paulo. Como procedimento metodológico adotou-se uma pesquisa qualitativa sobre a temática, sendo que seu desenvolvimento foi norteado por construção empírica (na forma de Estudo de Caso), a qual foi delimitado pelas compreensões advindas das realidades concretas e históricas que retratam o contexto social e jurídico, com a preocupação de obter um melhor entendimento da pandemia do Covid19 no município de Tupã/SP. A análise dos resultados foi orientada pelo aprofundamento do arcabouço científico, que consistiu na investigação organizada em três fases: pesquisa bibliográfica, exploração do tema - delimitadas às vezes no decorrer da pesquisa; a de coleta de dados; análise sistemática dos dados e informações como etapas primordiais para a redação final. A pesquisa verificou que o comercio aberto contribui para a manutenção econômica do município de Tupã, além de preservar os empregos dos tupãenses. Todavia, o que pode ser verificado é que o número de contaminados pelo COVID-19 é significativamente expressivo na faixa etária da população ativa (20 a 59 anos), ou seja, das pessoas que trabalham, o que poderia estar relacionado com números de idoso que vieram a falecer com a Covid-19.

PALAVRAS-CHAVE: Covid-19. Plano São Paulo. Tupã.

\section{ABSTRACT}

This article aimed to carry out an analysis of the Covid-19 pandemic in the municipality of Tupã, considering the legal measures adopted by the city to keep non-essential activities open, contrary to the recommendations of the Government of the State of São Paulo. As a methodological procedure, a qualitative research on the theme was adopted, and its development was guided by empirical construction (in the form of a Case Study), which was delimited by the understandings arising from the concrete and historical realities that portray the social and legal context, with the concern to obtain a better understanding of the Covid-19 pandemic in the municipality of Tupã / SP. The analysis of the results was guided by the deepening of the scientific framework, which consisted of the investigation organized in three phases: bibliographic research, exploration of the theme - sometimes delimited in the course of the research; data collection; systematic analysis of data and information as essential steps for final writing. The research found that open trade contributes to the economic maintenance of the municipality of Tupã, in addition to preserving the jobs of the Tupã people. However, what can be verified is that the number of people contaminated by COVID-19 is significantly expressive in the age group of the active population (20 to 59 years), that is, of the people who work, which could be related to numbers of elderly people who died with Covid-19.

KEYWORDS: Covid-19. São Paulo Plan. Tupã.

\section{ABSTRACTO}

Este artículo tuvo como objetivo realizar un análisis de la pandemia Covid-19 en el municipio de Tupã, considerando las medidas legales adoptadas por la ciudad para mantener abiertas las actividades no esenciales, en contra de las recomendaciones del Gobierno del Estado de São Paulo. Como procedimiento metodológico, se adoptó una investigación cualitativa sobre el tema, y su desarrollo estuvo guiado por la construcción empírica (en forma de Estudio de Caso), la cual fue delimitada por los entendimientos surgidos de las realidades concretas e históricas que retratan lo social y lo social. contexto legal, con la preocupación de obtener un mejor conocimiento de la pandemia Covid-19 en el municipio de Tupã / SP. El análisis de los resultados estuvo guiado por la profundización del marco científico, que consistió en la investigación organizada en tres fases: investigación bibliográfica, exploración del tema - en ocasiones delimitado en el transcurso de la investigación; recopilación de datos; Análisis sistemático de datos e información como pasos esenciales para la redacción final. La investigación encontró que el comercio abierto contribuye al mantenimiento económico del municipio de Tupã, además de preservar los empleos del pueblo Tupã. Sin embargo, lo que se puede verificar es que el número de personas contaminadas por COVID-19 es significativamente expresivo en el grupo de edad de la población activa (20 a 59 años), es decir, de las personas que trabajan, lo que podría estar relacionado con los números. de personas mayores que murieron con Covid-19.

PALABRAS CLAVE: Covid-19. Plan São Paulo. Tupã. 


\section{INTRODUÇÃO}

A pandemia do Covid-19 teve seu início em dezembro de 2019, quando a cidade de Wuhan, na China, vivenciou um surto de pneumonia, o qual só foi identificado pelos pesquisadores chineses como um novo coronavírus (SARS-CoV-2) em janeiro de 2021.

Não demorou, o vírus se espalhou para o resto do mundo. O primeiro caso no Brasil foi identificado em fevereiro de 2020. Desde então, o país vem acompanhando a escalada de contaminados e de vidas ceifadas.

A frente da administração do Sistema Único de Saúde - SUS, o Ministério da Saúde demostrou sua ingerência na condução da pandemia. Fato este que fez com que o Supremo Tribunal Federal, sem afastar a competência do Governo Federal, reconhecesse a autonomia dos Estados e Município para adotarem medidas de prevenção contra o Covid-19.

No Estado de São Paulo, foi implementado o Plano São Paulo que definiu restrições para conter o avanço da doença. Todavia, na contramão dessa política pública, o município de Tupã se recusou a seguir as determinações do plano e manteve as atividades não essenciais abertas durante a pandemia, amparado por Liminar deferida pelo Tribunal de Justiça de São Paulo.

\section{OBJETIVO}

Este artigo teve como objetivo realizar uma análise da pandemia do Covid-19 no município de Tupã, considerando as medidas jurídicas adotadas pela prefeitura em manter as atividades não essenciais abertas, contrariando as recomendações do Governo do Estado de São Paulo.

\section{METODOLOGIA}

Como procedimento metodológico adotou-se uma pesquisa qualitativa sobre a temática, sendo que seu desenvolvimento foi norteado por construção empírica (na forma de Estudo de (aso), a qual foi delimitado pelas compreensões advindas das "realidades concretas e históricas" (DEMO, 1995), que retratam o contexto social e jurídico, com a preocupação de obter um melhor entendimento da pandemia do Covid-19 no município de Tupã/SP.

A análise dos resultados foi orientada pelo aprofundamento do arcabouço científico, que consistiu na investigação organizada em três fases: pesquisa bibliográfica, exploração do tema - delimitadas às vezes no decorrer da pesquisa; a de coleta de dados; análise sistemática dos dados e informações como etapas primordiais para a redação final (LÜDKE; ANDRÉ, 1986, p. 21).

Sob esse ângulo, nas observações e análise dos dados e informações o posicionamento é o de fugir da forma naturalizada da visão dos fenômenos, que os desliga de sua origem, distanciando-os de suas determinações reais.

A consideração desses aspectos permite a busca da essência do fenômeno na sua configuração particular, nesse caso, verificar a efetividade medidas jurídicas adotadas pela prefeitura em manter as atividades não essenciais abertas, contrariando as recomendações do Governo do Estado de São Paulo. 
Essa configuração, bem como a apreensão de sua essência, requer o estudo de caso, ou seja, o aprofundamento característico das pesquisas assim denominadas. Neste sentido, deve-se ainda ser ressaltado, que os dados quantitativos serão incluídos com o intuito de inserir a pesquisa em um contexto amplo, essencial para sua compreensão.

\title{
2 PANDEMIA DO COVID-19
}

Segundo dados da Organização Mundial de Saúde (OMS) ${ }^{1}$ o surto da COVID-19, doença causada pelo coronavírus denominado SARS-CoV-2, iniciou-se na cidade de Wuhan, localizada na província de Hubei, na China, em dezembro de 2019 , onde se espalhou rapidamente entre as populações.

\begin{abstract}
Os coronavírus são uma grande família de vírus comuns em muitas espécies diferentes de animais, incluindo camelos, gado, gatos e morcegos. Raramente, os coronavírus que infectam animais podem infectar pessoas, como exemplo do MERS-CoV e SARS-CoV. Recentemente, em dezembro de 2019, houve a transmissão de um novo coronavírus (SARS-CoV-2), o qual foi identificado em Wuhan na China e causou a COVID-19, sendo em seguida disseminada e transmitida pessoa a pessoa. ${ }^{2}$
\end{abstract}

Enquanto doença, a Covid-19 apresenta um espectro clínico variando de infecções assintomáticas a quadros graves. De acordo com a OMS, "a maioria (cerca de $80 \%$ ) dos pacientes com COVID-19 podem ser assintomáticos ou oligo sintomáticos (poucos sintomas), e aproximadamente $20 \%$ dos casos detectados requer atendimento hospitalar por apresentarem dificuldade respiratória" ${ }^{3}$, sendo que aproximadamente $5 \%$ podem vir a necessitar de suporte ventilatório.

Os sintomas da Covid-19 podem se apresentar como uma simples gripe a uma "Síndrome Gripal-SG (presença de um quadro respiratório agudo, caracterizado por, pelo menos, dois dos seguintes sintomas: sensação febril ou febre associada a dor de garganta, dor de cabeça, tosse, coriza) até uma pneumonia severa" ${ }^{4}$. Segundo Ministério da Saúde a transmissão acontece de uma pessoa doente para outra ou por contato físico como toque do aperto de mão contaminada, objetos ou superfícies contaminadas e, ainda, por intermédio de gotículas de saliva, espirro, tosse, dentre outros.

Frente a este quadro, tornou-se necessário o distanciamento social como medida preventiva para conter a transmissão do Covid-19, além das recomendações do Ministério da Saúde para lavar as mãos com água e sabão ou higienizar com álcool $70^{\circ} \mathrm{em}$ gel, várias vezes o dia.

Deve-se destacar que medidas como o distanciamento social constitui um esforço para diminuir o contato físico entre as pessoas, com objetivo reduzir a propagação e contágio do Covid-19. Já o isolamento é utilizado para separar uma pessoa infectadas daqueles que venham

1 ORGANIZAÇÃO MUNDIAL DE SAÚDE (OMS). Coronavirus disease 2019 (COVID-19). Disponível em: https://www.who.int/docs/default-source/coronaviruse/situation-reports/20200121-sitrep-1-2019-

ncov.pdf?sfvrsn=20a99c10_4 . Acesso 01 abr. 2021.

2 BRASIL. O que é Covid-19. Ministério da Saúde. Disponível em: https://coronavirus.saude.gov.br/sobre-a-doenca . Acesso em 25 mar. 2021.

3 Ibid.

4 BRASIL. Quais são os sintomas. Ministério da Saúde. Disponível em: https://coronavirus.saude.gov.br/sobre-adoenca. Acesso em 25 mar. 2021. 


\section{Revista Científica ANAP Brasil}

ISSN 1984-3240 - Volume 14, número 32, 2021

apresentar um quadro assintomático, enquanto a quarentena é forma evitar a circulação de pessoas que tenham tido contato com pessoas contaminadas pela a doença (WILDER-SMITH; FREEDMAN, 2020). Segundo Duarte et al. (2020, p. 3402) os estudos com a "população da China, primeiro país que adotou a quarentena e o isolamento social como medidas protetivas à disseminação do novo coronavírus".

Em 30 de janeiro de 2020, a OMS declarou que a epidemia da COVID-19 constituía uma Emergência de Saúde Pública de Importância Internacional (ESPII), e, em 11 de março de 2020, uma pandemia. Mores, Fokers e Fauci (2009) explicam que as pandemias podem ser caracterizadas como epidemias com a capacidade de afetar uma quantidade expressiva de pessoas em diversos países.

No Brasil, o Ministério da Saúde declarou a Emergência em Saúde Pública de Importância Nacional (Portaria no 188 de 03 de fevereiro de 2020), em decorrência da infecção humana pelo novo coronavírus (Sars-CoV-2), permitindo assim, a implementação de medidas e ações administrativas para o enfrentamento da pandemia. O primeiro caso de infecção pelo Covid-19 em território nacional, notificado pelo Ministério da Saúde no dia 26 de fevereiro, no Estado de São Paulo, o que fez com que país entrasse em alerta.

Desde então, verificou-se que a evolução da doença no mundo, assim como no Brasil, elevou de forma expressiva o número de óbitos e, que, somente medidas de isolamento social tem apresentado resultados eficientes para conter o avanço da contaminação pelo vírus. Sem medicamento eficaz para o combate da doença, os médicos se desdobram em esforços para prolongar a vida de seus pacientes, por intermédio de ventilação mecânica.

Em 2020, o Brasil passou pela primeira onda da doença, o que ceifou inúmeras vidas de brasileiros, demonstrando a carência do Sistema Único de Saúde - SUS, principalmente em ofertar leitos de Unidades de Tratamento Intensivos - UTIs.

Para conter a pandemia, disparou a corrida entre os países e farmacêuticas para o desenvolvimento de uma vacina para imunização da população contra o Covid-19. Em 8 de dezembro de 2020, o Reino Unido se tornou o "primeiro país do Ocidente a vacinar a população contra o novo coronavírus. $O$ imunizante aprovado para o uso emergencial foi o desenvolvido pela parceria entre a farmacêutica americana Pfizer e a empresa de biotecnologia alemã BioNTech"5.

No Brasil, após a autorização pela ANVISA do uso emergencial da vacina da CoronaVac e Oxford-AstraZeneca, no dia 17 de janeiro de 2021, a enfermeira Mônica Calazans de 54 anos, que atuava na linha frente do combate ao coronavírus no Hospital Emílio Ribas, foi a primeira brasileira a receber a primeira de duas doses do imunizante contra o Covid-196.

Todavia, janeiro de 2021 foi marcado pelo colapso no sistema de saúde da Amazonia, onde milhares de amazonenses perderam a vida em decorrência de complicações causadas pelo Covid-19 e da falta de infraestrutura do sistema de saúde para atender a alta demanda. $O$ fato chamou a atenção do mundo, pois foi detectado uma mutação do vírus na proteína Spike, que faz a interação inicial com a célula humana ${ }^{7}$, o que torna o vírus ainda mais transmissível.

\footnotetext{
${ }^{5}$ Disponível em: https://www.cnnbrasil.com.br/saude/2020/12/24/quais-os-paises-que-ja-comecaram-a-vacinacaocontra-a-covid-19. Acesso em 20 mar. 2021.

6 Disponível em: https://exame.com/brasil/enfermeira-de-sp-e-a-primeira-pessoa-vacinada-contra-covid-19-nobrasil/ . Acesso 20 mar. 2021.

7 Disponível em: https://agenciaaids.com.br/noticia/mutacao-do-virus-no-amazonas-o-que-se-sabe-ate-agora/ . Acesso 20 mar. 2021.
} 


\section{Revista Científica ANAP Brasil}

ISSN 1984-3240 - Volume 14, número 32, 2021

Apesar das medidas de prevenção para combater o processo de contaminação do Covid-19, nos primeiros meses de 2021, o Brasil passa pela segunda onda da doença. O mês de março de 2021 já é considerado o mês mais letal (Figura 01).

Figura 01 - Março de 2021 é o mês mais letal

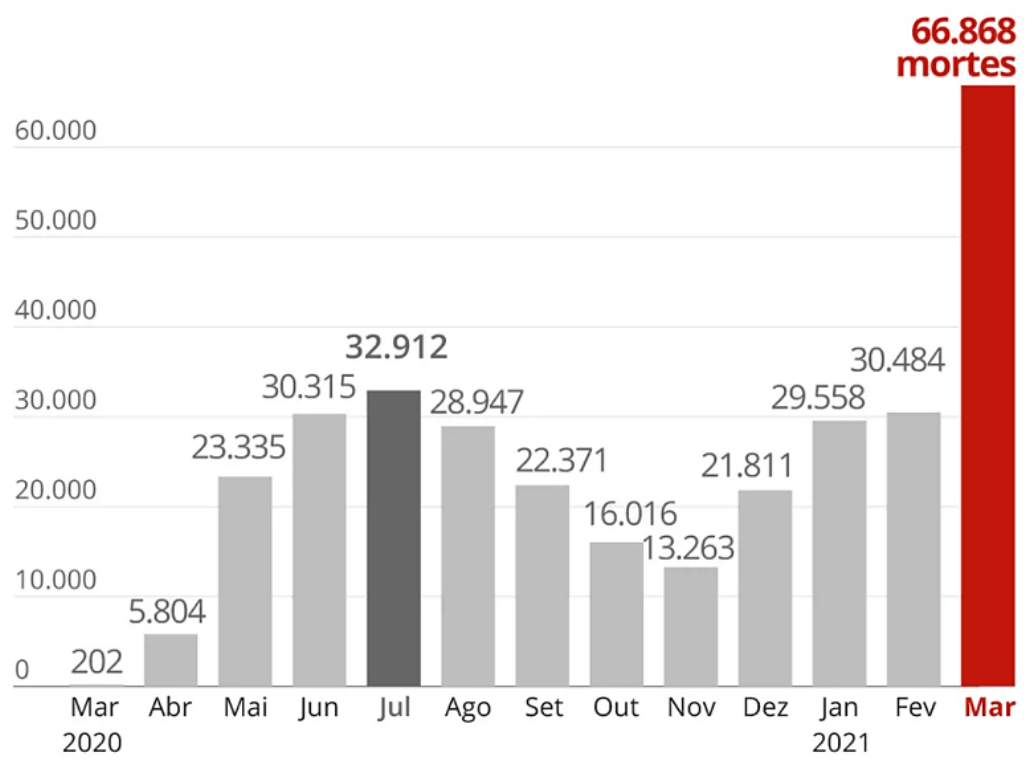

Fonte: Consórcio de veículos de imprensa a partir de dados das secretarias estaduais de Saúde, 31 mar. 2021.

Foto: Editoria de Arte/G18

De acordo com as Portal $\mathrm{G1}^{9}$, "a média móvel de mortes no país nos últimos 7 dias chegou a 2.971, pior marca no índice pelo 6ㅇ dia consecutivo. Em comparação à média de 14 dias atrás, a variação foi de $+42 \%$, indicando tendência de alta nos óbitos pela doença". Esses dados indicam que o Brasil apresenta pela 1a vez mais de 20 mil vidas perdidas em uma semana. Os dados revelam que são 70 dias seguidos com a média móvel de mortes acima da marca de mil, sendo que o país completa agora 15 dias com essa média acima dos 2 mil mortos por dia, aproximando-se agora da média de 3 mil vidas perdidas por dia.

Segundo dados do Ministério da Saúde no Brasil e da plataforma Worldometer ${ }^{10}$, no dia 30 de março de 2021, o Brasil teve 3.780 vidas perdidas para o Covid-19, sendo o país com mais registros em 24 horas em todo o mundo (Figura 02).

\footnotetext{
8 Disponível em: https://g1.globo.com/bemestar/coronavirus/noticia/2021/03/31/brasil-registra-quase-4-milmortes-por-covid-no-dia-e-fecha-pior-mes-da-pandemia-com-668-mil-obitos.ghtml. Acesso em 03 abril 2021.

9 Disponível em: https://g1.globo.com/bemestar/coronavirus/noticia/2021/03/31/brasil-registra-quase-4-milmortes-por-covid-no-dia-e-fecha-pior-mes-da-pandemia-com-668-mil-obitos.ghtml . Acesso em 03 abril 2021.

10 Fonte: https://www.poder360.com.br/coronavirus/covid-19-brasil-supera-vitimas-diarias-de-outros-9-paisessomados/. Acesso 3 abril 2021.
} 


\section{Revista Científica ANAP Brasil}

ISSN 1984-3240 - Volume 14, número 32, 2021

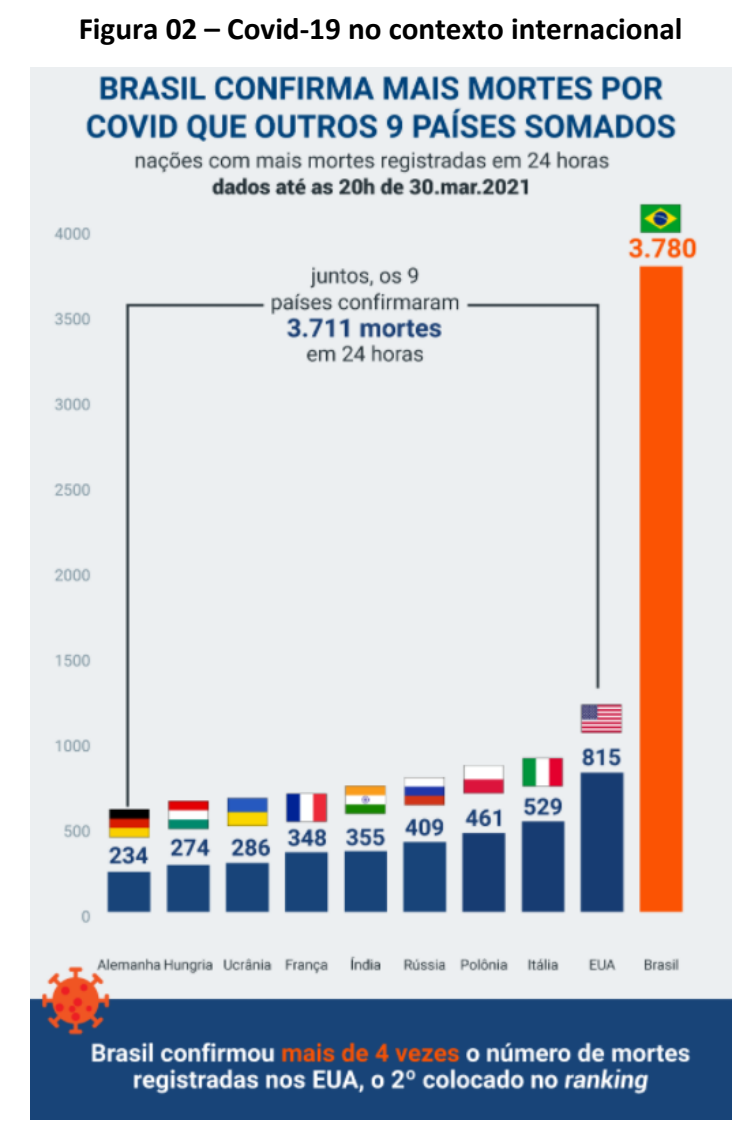

Fonte: Ministério da Saúde (Brasil) e Woridometer (demais países).

De acordo com Consórcio de veículos de imprensa ${ }^{11}$ a partir de dados das secretarias estaduais de Saúde (2021), até o dia 03 de abril de 2021, o Brasil registou já tinha registrado 328.366 mortes (Figura 03) e 12.912.379 casos de contaminação pelo Covid-19 (Figura 04). Segundo esses dados, o país apresenta uma média móvel de óbitos por dia apresenta uma alta de 35\%.

Figura 03 - Morte por Covid-19 por dia

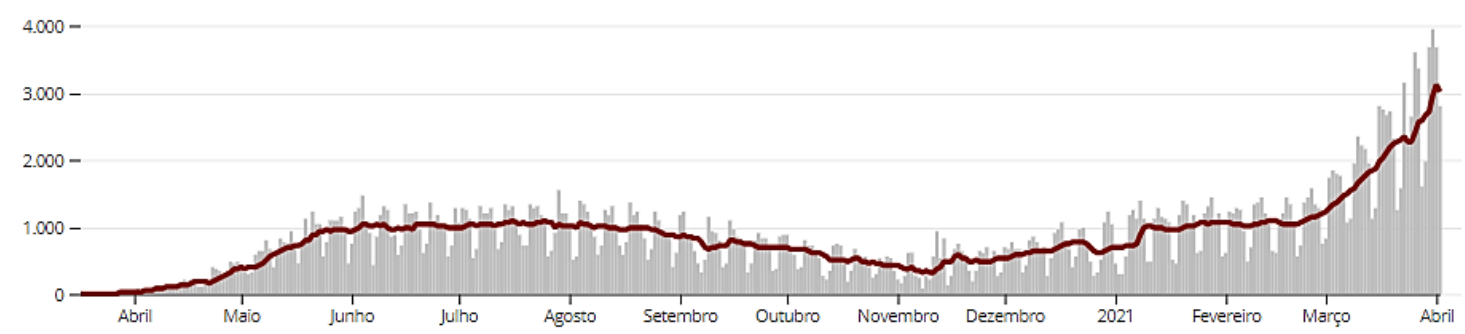

Fonte: Consórcio de veículos de imprensa a partir de dados das secretarias estaduais de Saúde, 3 abril 2021.

${ }^{11}$ Fonte: https://especiais.g1.globo.com/bemestar/coronavirus/estados-brasil-mortes-casos-media-movel/ . Acesso 3 abril 2021. 


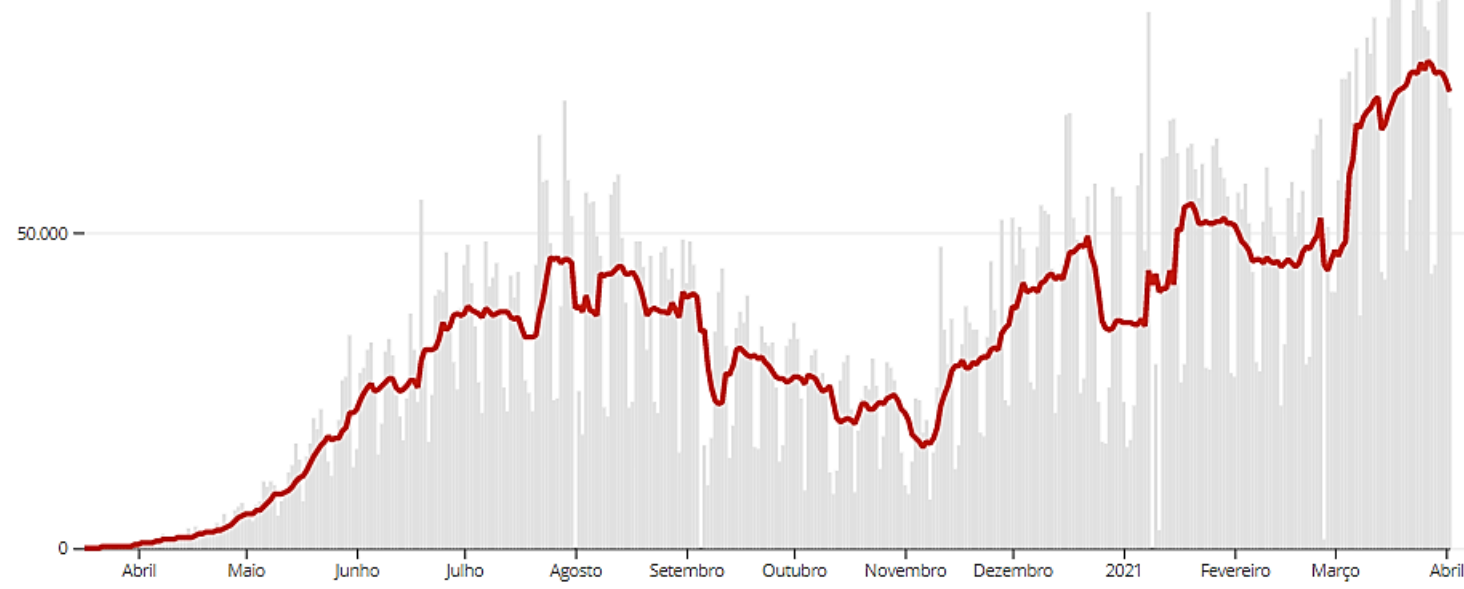

Fonte: Consórcio de veículos de imprensa a partir de dados das secretarias estaduais de Saúde, 3 abril $2021 .{ }^{12}$

Para conter o avanço da pandemia no Brasil, até o dia 3 de abril de 2021, 19.183.802 pessoas já tinham recebido a primeira dose de vacina contra a Covid-19, sendo que a segunda dose tinha sido aplicada em 5.342.361 pessoas que corresponde a 2,52\% da população ${ }^{13}$.

Diante do cenário apresentado, com ausência de medicamentos eficazes para o combate do Covid-19, ausência de infraestrutura do sistema de saúde (público e particular), falta de insumos básicos como oxigênio, somado a lentidão no processo de imunização da população brasileira, ressalta-se a importância das medidas de prevenção para combater o processo de contaminação da doença, a exemplo do distanciamento social e a higienização das mãos.

\section{ESTUDO DE CASO DA ESTÂNCIA TURÍSTICA DE TUPÃ/SP}

A Estância Turística de Tupã está localizada a oeste do Estado de São Paulo, tendo como limites territoriais uma área de $628,5 \mathrm{~km}^{2}$, que abrange os Distritos de Varpa, Universo, Parnaso e a cidade de Tupã. O Município faz divisa com os municípios de Arco-Íris, Herculândia, Quintana, Quatá, Bastos, João Ramalho e lacri (Figura 05).

\footnotetext{
12 Disponível em: https://especiais.g1.globo.com/bemestar/coronavirus/estados-brasil-mortes-casos-media-movel/ .Acesso 3 abr. 2021.

13 Disponível em: https://g1.globo.com/bemestar/vacina/noticia/2021/04/03/brasil-aplicou-ao-menos-uma-dosede-vacina-em-mais-de-191-milhoes-aponta-consorcio-de-veiculos-de-imprensa.ghtml . Acesso 4 abr. 2021.
} 


\section{Revista Científica ANAP Brasil}

ISSN 1984-3240 - Volume 14, número 32, 2021

Figura 05 - Localização do Município de Tupã/SP

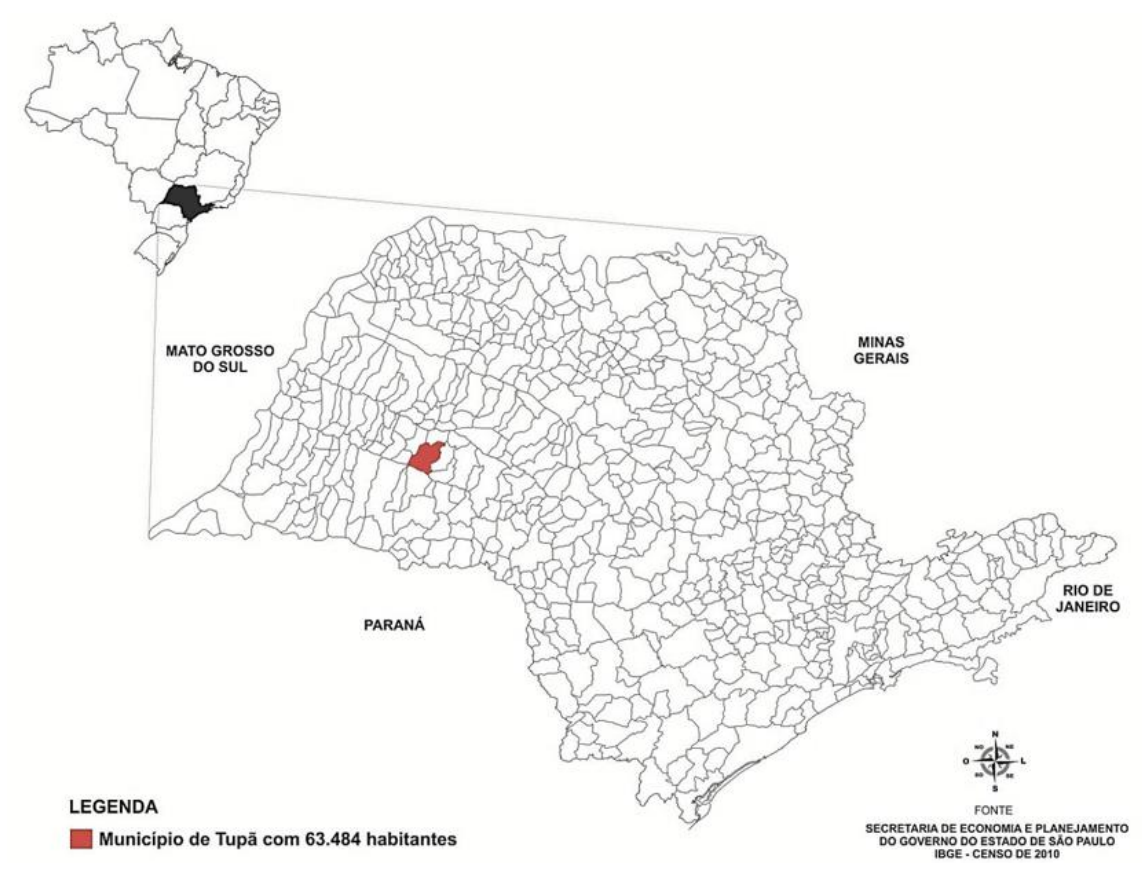

Segundo o IBGE $^{14}$ (2010) a população da Estância Turística de Tupã, encontra-se distribuída entre 60.930 pessoas residentes na área urbana e 2.546 na área rural. 0 grau de urbanização no município é de 95\%, enquanto que a média do Estado de São Paulo é de 95,94\%.

Em 2010, a cidade de Tupã apresentou o Índice de Desenvolvimento Humano Municipal - IDHM ${ }^{15}$ de 0,771\%, enquanto o do Estado de São Paulo apontou 0,783\% (SEADE, 2014). Em período anterior, o Censo Municipal $(2007){ }^{16}$ revelou um índice de desigualdade na distribuição de renda da população, uma vez que $18,01 \%$ da população tinha renda familiar de até 1 salário mínimo, entretanto ao se considerar a renda familiar da população que recebe até 3 salários mínimos, este valor sobe para 72,85\%.

Este contexto foi reafirmado pelo censo em 2010, onde o IBGE vem reforçar essa tendência, ao aferir o número de famílias residentes em domicílios particulares com classe de rendimento nominal mensal familiar per capita (Figura 06).

\footnotetext{
${ }^{14}$ IBGE - Instituto Brasileiro de Geografia e Estatística.

15 Segundo SEADE (2014), Índice de Desenvolvimento Humano Municipal - IDHM (Indicador que sintetiza três aspectos do desenvolvimento humano: vida longa e saudável, acesso a conhecimento e padrão de vida, traduzidos nas dimensões de longevidade, educação e renda). Disponível em: < http://produtos.seade.gov.br/produtos/perfil/perfilMunEstado.php > Acesso 20 ago. 2014.

${ }^{16}$ Censo Municipal da Estância Turística de Tupã, realizado em julho de 2007, segundo informações da SEPLIN Secretaria Municipal de Planejamento e Infraestrutura, 2012.
} 


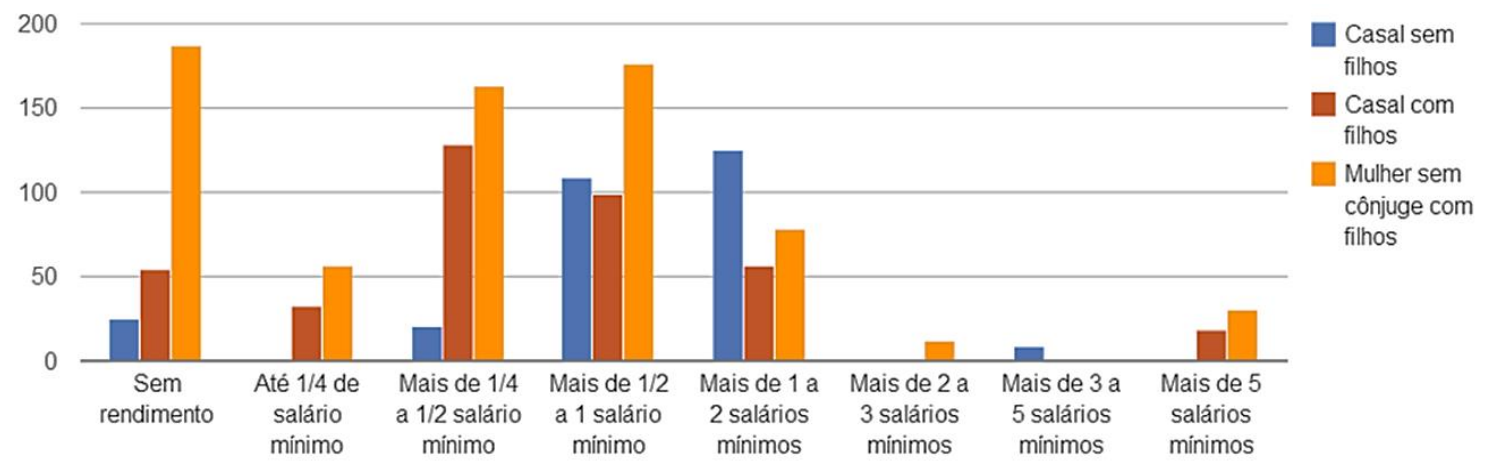

Fonte: IBGE, 2010.

Conforme pode ser constatado nos dados do Censo Municipal (2007) e do IBGE (2010), onde a população é predominantemente baixa renda, o que vem reforçar a necessidade de implementação de Políticas Públicas voltadas ao enfretamento das demandas socioeconômicas apontadas nas duas pesquisas descritas acima.

Em linhas gerais, a economia da cidade está estruturada no comércio local, indústria e agronegócio, onde o setor comercial é composto por estabelecimentos ligados ao varejo: mercados, mercearias, vestuário e materiais para construção, bem como, pela oferta da prestação de serviços de profissionais liberais, autônomos entre outros. Na região, o Município é destaque na indústria de transformação, sendo que no campo a economia está baseada no agronegócio (BENINI, 2015).

\subsection{Covid-19 no município de Tupã/SP}

Em 9 de março de 2020, a prefeitura de Tupã (SP) confirmou o primeiro caso de contaminação pelo Covid-19, foi de um homem de 34 anos que trabalhava em São Paulo e que teve contato com uma pessoa contaminada. Na ocasião, a Vigilância Epidemiológica já vinha monitorando mais 10 casos suspeitos ${ }^{17}$.

Para o enfrentamento da pandemia, a pesquisa constatou que o município de Tupã conta com 20 leitos clínicos de enfermaria e 15 leitos de UTI - Unidade Terapia Intensiva da Santa Casa de Tupã exclusivo para tratamento de Covid-19, o que trouxe certa tranquilidade para população tupãense, considerando que muitos municípios do interior do Estado de São Paulo, não contam com a ofertas de UTIs.

A primeira morte por Covid-19 foi registrada em 25 de abril de 2020. A vítima foi mulher de 45 anos que já estava entubada na UTI da Santa Casa, apresentou um agravamento do seu quadro clínico, vindo a óbito ${ }^{18}$.

Como medida preventiva, o município Tupã manteve fechadas creches e escolas da Rede de Ensino Municipal, desde o início da pandemia até então, oferecendo para os alunos, apenas o ensino online. Alguns espaços públicos como praças e parques, receberam restrições de uso durante a faze vermelha do Plano São Paulo, de modo a evitar aglomerações.

\footnotetext{
17 Disponível em: https://www.tupa.sp.gov.br/noticia/6492/tupa-tem-primeiro-caso-confirmado-decoronavirus.html . Acesso em 20 mar.2021.

18 Disponível em: https://www.tupa.sp.gov.br/noticia/6529/tupa-registra-1-obito-em-decorrencia-docoronavirus.html . Acesso em 20 marc.2021.
} 


\section{Revista Científica ANAP Brasil}

ISSN 1984-3240 - Volume 14, número 32, 2021

A pesquisa constatou que apesar do Município ter que seguir o Plano São Paulo ${ }^{19}$, o prefeito de Tupã, Caio Aoqui, conseguiu no dia 5 de maio de 2020, liminar junto ao Tribunal de Justiça do Estado do Estado de São Paulo, deferida pelo desembargador José Jacob Valente que autorizou a flexibilização do comercio na cidade, a partir de 11 de maio de 2020.

Em 3 de abril de 2021, o município acumulava 3.349 casos de pessoas que foram contaminadas pelo Covid-19 e 104 pessoas que morreram em decorrência de agravamento e complicações da doença.

A Figura 07 revela que quem mais contraiu a doença, são pessoas ativas no mercado de trabalho com faixa etária de 20 a 59 anos. Esses números denotam possível relação com política adotada pelo poder público municipal que se utilizou de instrumentos jurídicos para manter o comercio aberto, ignorando as recomendações do Plano São Paulo.

\section{Figura 07 - Casos e óbitos de Covid em Tupã/SP}

\section{CASOS}

FAIXA ETÁRIA

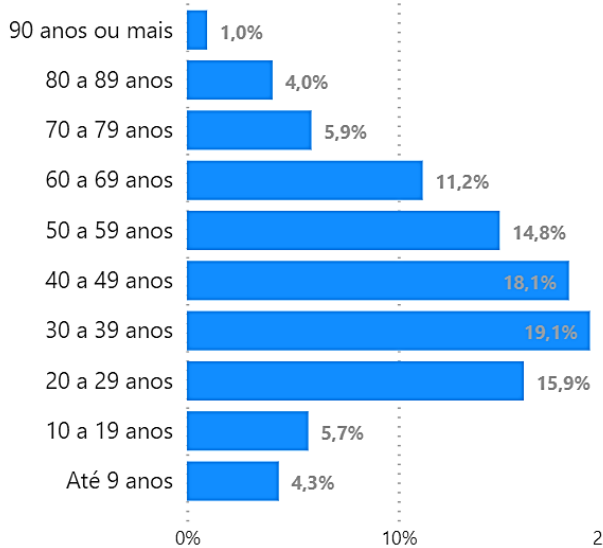

ÓBITOS

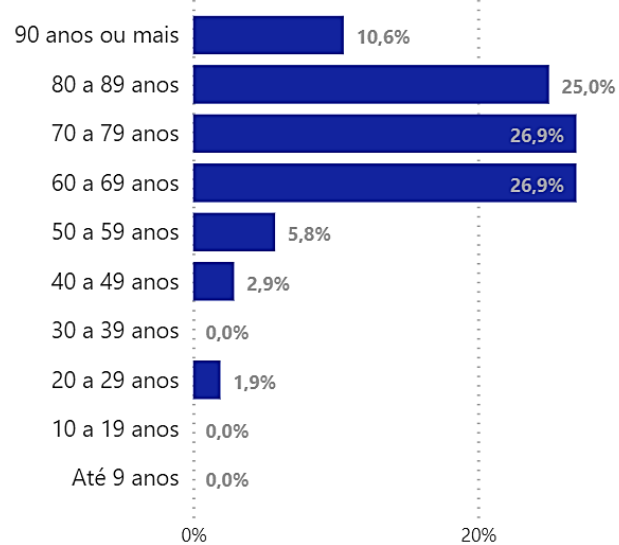

Fonte: SEADE, 2021. ${ }^{20}$

Em 13 de julho de 2020, a Casa Emanuel apresentou um surto de contaminação por Covid-19 que resultou em óbito conjunto de 15 idosos que eram abrigados pela instituição. Em fevereiro de 2021, a Casa dos velhos de Tupã noticiou 3 mortes decorrentes de outro surto de contaminação por Covid-1921.

Os casos de óbitos no município foram acentuados na faixa etária de 60 a 90 anos de idade, o que denota a vulnerabilidade dos idosos frente a Covid-19, decorrentes de doenças preexistentes, como cardiopatia, diabetes, doenças neurológicas, obesidades, dentre outras (Figura 08).

\footnotetext{
${ }^{19}$ Deve-se destacar que o Plano São Paulo prevê flexibilização da quarentena segundo critérios técnicos, como taxa de ocupação de leitos, índice de isolamento social e achatamento da curva de contágio do coronavírus, conforme especificado no Decreto Estadual no 64.881/2020.

20 Disponível em: https://www.seade.gov.br/coronavirus/\# Acesso em 03 abr. 2021

21 Disponível em: https:/g1.globo.com/sp/bauru-marilia/noticia/2020/08/10/tupa-confirma-15a-morte-de-idosode-asilo-com-surto-de-covid-19.ghtml . Acesso 27 mar. 2021.
} 


\section{Revista Científica ANAP Brasil}

ISSN 1984-3240 - Volume 14, número 32, 2021

Figura 08 - Doenças preexistentes associadas casos e óbitos de Covid em Tupã/SP

CASOS

\begin{tabular}{r|r|r} 
Cardiopatia & $6,1 \%$ \\
Diabetes & $4,5 \%$ \\
Doença Neurológica & $1,8 \%$ \\
Obesidade & $0,6 \%$ \\
DoENÇAS & Doença Renal & $0,6 \%$ \\
PrEEXISTENTES** & Pneumopatia & $1,1 \%$ \\
Imunodepressão & $0,5 \%$ \\
Asma & $0,4 \%$ \\
Doença Hematológica & $0,0 \%$ \\
Doença Hepática & $0,1 \%$ \\
Síndrome de Down & $0,1 \%$
\end{tabular}

$0 \%$

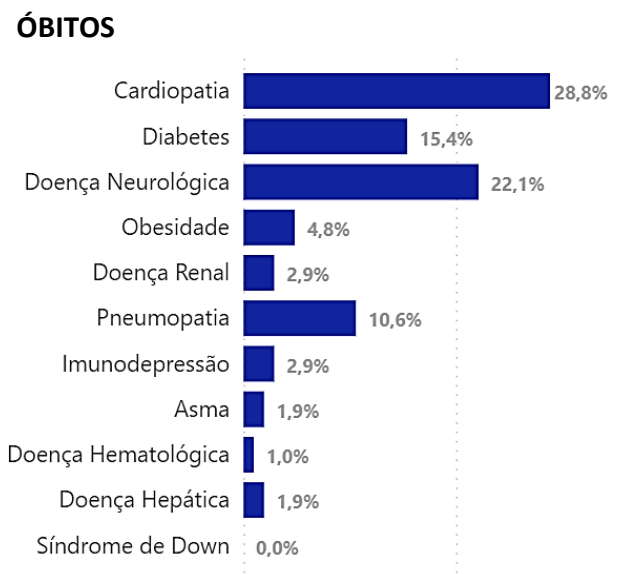

$0 \% \quad 20 \%$

Fonte: SEADE, 2021. ${ }^{22}$

Com mais de 63.010 óbitos no Estado de São Paulo somado com as taxas de ocupação dos leitos de UTIs do Estado em 87,6\% e na grande São Paulo com 86,7\%, o governador do Estado de São Paulo no dia 11 de março de 2021, implementou a Fase Emergencial do Plano São Paulo, aumentando as medidas restritivas para conter o avanço da pandemia.

No dia 16 de março de 2021, devido ao aumento da contaminação e evolução da covid19 no município, a taxa de ocupação dos leitos de UTI (Unidade de Terapia Intensiva) da Santa Casa local atingiu 100\%. O Secretário Municipal de Saúde de Tupã (SP), Miguel Ângelo de Marchi, enfatizou:

Estamos já na fase de escolher quem são os pacientes que vão ser internados, quem são os pacientes que vão para uma UTI, quem são os pacientes que podem ir para um tubo. Hoje não se escolhe o mais idoso ou mais jovem, hoje se escolhe aquele que tem mais possibilidade de vida. Aquele que pode ser mais produtivo no futuro e isso, infelizmente, vai chegar a aumentar o número de óbitos. ${ }^{23}$

Apesar do protocolo anunciado para internações nas UTIs, a Administração Municipal optou por seguir com as atividades não essências abertas, contrariando a Fase Emergencial do Plano São Paulo.

Para tal propósito, em observância do Princípio da Legalidade, a Prefeitura de Tupã publicou no dia 22 de março de 2021 o Decreto 9.014, com as medidas e regras para o funcionamento das atividades durante a fase emergencial, que é a mais restritiva do Plano São Paulo. No dia seguinte, o Ministério Público buscou assistência junto ao Poder Judiciário, deferida liminar para impedir o funcionamento de atividades não essenciais no município, especialmente no que diz respeito ao distanciamento social seletivo em restaurantes, lanchonetes e afins, que funcionavam em desacordo com as regras estaduais.

\footnotetext{
22 Disponível em: https://www.seade.gov.br/coronavirus/\# Acesso em 03 abr. 2021

23 Disponível em: https://noticias.uol.com.br/saude/ultimas-noticias/redacao/2021/03/16/tupa-covid-19.htm Acesso em 3 abr. 2021.
} 


\section{Revista Científica ANAP Brasil}

ISSN 1984-3240 - Volume 14, número 32, 2021

Todavia, após recurso junto a 13a Câmara de Direito Público do Tribunal de Justiça de São Paulo, o desembargador Borelli Thomaz, suspendeu a liminar que impedia os efeitos do decreto municipal que regulamentava a abertura do comércio.

A pesquisa constatou que no período de 30 dias, entre os dias 4 de março e 3 de abril de 2021 , foram noticiados 20 óbitos, o que representa um aumento de $23 \%$. Segundo o Boletim Epidemiológico de 01 de abril de 2021, o município de Tupã apresentava uma taxa de ocupação de $80 \%$ dos leitos de enfermaria e $93,3 \%$ dos leitos de UTI na Santa Casa de Tupã24.

De modo a monitorar o avanço da contaminação da Covid-19, até o dia 3 de abril de 2021, o município já tinha realizado um total de 15.785 exames, dentre os quais 12.354 resultados negativos. Dentre o número de casos confirmados temos 3.376, sendo que 142 ainda em período de transmissão, além de 55 casos suspeitos, incluindo 1 óbito ${ }^{25}$. Ressalta-se que, até o dia 3 de abril de 2021, não foi identificada a mutação do coronavírus originária do Amazonas no município, o que certamente tem contribuído para um número reduzido de contaminados e mortes.

Dentro do Programa de Imunização do Governo de São Paulo, foram disponibilizadas doses da vacina da CoronaVac fornecida pelo Instituto Butantã e Oxford-AstraZeneca fornecida pela Fiocruz. Para conter o avanço da Covid-19, até o dia 3 de abril de 2021, o município de Tupã já havia vacinado 10.979 pessoas com a 1 a dose o que representa $16,8 \%$ de sua população e 3.494 pessoas com a 2 a Dose $^{26}$.

\section{CONSIDERAÇÕES FINAIS}

A pesquisa verificou que o comercio aberto contribui para a manutenção econômica do município de Tupã, além de preservar os empregos e renda dos tupãenses. Todavia, o que pode ser verificado é que o número de contaminados pelo COVID-19 é significativamente expressivo na faixa etária da população ativa (20 a 59 anos), ou seja, das pessoas que trabalham. O que demonstra que a abertura das atividades não essenciais pode ter contribuído para disseminação da doença.

Ressalta-se ainda, o número de pessoas que vieram a óbito em decorrência do Covid19, representados por uma parcela significativa do grupo de risco (60 a 90 anos) e não puderam ser preservados do contágio, considerando o convívio com pessoas da faixa etária ativa da população.

Neste sentido, frente as políticas públicas adotadas, a exemplo do município de Tupã, defende-se que a única maneira de conter a disseminação do vírus, a escalada de pessoas contaminadas e os óbitos, é com a vacinação em massa da população.

\footnotetext{
24 Disponível em: https://www.radiotupa.com.br/tupa-registra-mais-35-casos-negativos-27-positivos-e-28pacientes-recuperados-de-coronavirus/ . Acesso 3 abr. 2021.

25 Disponível em: https://www.radiotupa.com.br/tupa-registra-mais-35-casos-negativos-27-positivos-e-28pacientes-recuperados-de-coronavirus/ . Acesso 3 abr. 2021.

26 Disponível em: https://vacinaja.sp.gov.br/vacinometro/?utm_source=portal\&utm_medium=bannertopo\&utm_campaign=Vacinometro-Municipios . Acesso 3 abr. 2021.
} 


\section{Revista Científica ANAP Brasil}

ISSN 1984-3240 - Volume 14, número 32, 2021

\section{REFERÊNCIAS}

BENINI, Sandra Medina. Infraestrutura verde como prática sustentável para subsidiar a elaboração de planos de drenagem urbana: estudo de caso da cidade de Tupã/SP. Tese (doutorado) - Universidade Estadual Paulista, Faculdade de Ciências e Tecnologia. Presidente Prudente, 2015.

DEMO, Pedro. Metodologia científica em ciências sociais. 3. Ed. rev. e ampl. São Paulo: Atlas, 1995.

DUARTE, M. Q. et al.. COVID-19 e os impactos na saúde mental: uma amostra do Rio Grande do Sul, Brasil. Ciênc. saúde coletiva, 25 (9) $28 \mathrm{Ago/Set}, 2020$.

LÜDKE, Menga; ANDRÉ, Marli E. D. A. Pesquisa em educação: abordagem qualitativa. São Paulo: EPU, 1986, 99 p. MORENS, D.M.; FOLKERS, G.K.; FAUCI, A.S. What is a pandemic? J Infect Dis. 200 (7):1018-1021, 2009.

WILDER-SMITH, A.; FREEDMAN, D.O. Isolation, quarantine, social distancing and community containment: pivotal role for old-style public health measures in the novel coronavirus (2019-nCoV) outbreak. J Travel Med. 27(2), 2020 